\title{
Aníbal Quijjano em seu labirinto: metamorfoses teóricas e utopias políticas
}

Deni Alfaro Rubbo*

\section{Resumo}

O objetivo deste artigo é discutir alguns desdobramentos presentes na trajetória intelectual e política de Aníbal Quijano (1930-2018). Procura-se reconstruir especialmente o contexto de "crise dos paradigmas" das ciências sociais e de declínio da esquerda marxista, que se manifestaram de modo acentuado na década de 1980, examinando como o sociólogo peruano encontrou soluções para a encruzilhada histórica que se anunciava a uma geração de cientistas sociais engajados na América Latina. Parte-se da hipótese de que a cristalização de um ciclo de derrotas políticas possibilitou um novo redirecionamento teórico para Quijano entender a história latino-americana em sua moldura política e epistêmica. Por fim, analisa-se o movimento de aproximação e distanciamento que o autor faz com a tradição marxista a partir da perspectiva adotada da "colonialidade do poder".

Palavras-chave: Aníbal Quijano, América Latina, marxismo, ciências sociais, colonialidade.

\footnotetext{
* Universidade Estadual do Mato Grosso do Sul, MS, Brasil.
} 


\section{Aníbal Quijano in his labyrinth: theoretical metamorphoses and political utopias}

Abstract

This article discusses some developments in the intellectual and political trajectory of Aníbal Quijano (1930-2018). It seeks to reconstruct the context of the social sciences' "crisis of paradigms" and the decline of the Marxist left, both markedly manifest in the 1980s, by examining how the Peruvian sociologist found solutions to the historical crossroads posed to a generation of activist social scientists in Latin America. It is hypothesized that the crystallization of a cycle of political defeats made possible for Quijano a new theoretical redirection towards understanding the history of Latin America in its political and epistemic framework. Finally, the author's movements of approach toward and detachment from the Marxist tradition based on the perspective of "coloniality of power" is analyzed.

Keywords: Aníbal Quijano, Latin America, Marxism, social sciences, coloniality.

\section{Crise e crítica: (des)encontros históricos nas ciências sociais da América Latina}

$\mathrm{H}$ istoricamente, o encontro entre ciências sociais e América Latina foi institucionalizado depois da Segunda Guerra Mundial. Em particular, nas décadas de 1960 e 1970, a sociologia latinoamericana teve uma farta produção original cuja ressonância ultrapassou as fronteiras do continente e instaurou um espaço no conjunto na república mundial das ciências sociais. Os últimos cinquenta anos da história do pensamento crítico latino-americano confundem-se com biografias de intelectuais de uma geração de sociólogos engajados, que atravessaram um período de transição histórica e de derrotas políticas diante das vicissitudes do capitalismo periférico na região. A trajetória de Aníbal Quijano (19302018) é um exemplo incontornável que se confunde com a história das ciências sociais na América Latina. Com uma vasta e densa produção intelectual de mais de meio século, entre inflexões teóricas e utopias 
políticas, a contribuição do sociólogo peruano é uma das mais profícuas para o debate teórico que aflige o destino do continente.

Com o falecimento de Quijano, em maio de 2018, uma avalanche de seminários com depoimentos e análises foi realizada em universidades latino-americanas, a fim de homenagear o autor e sua obra. Decerto, isso se converterá em uma nova tendência no decorrer dos próximos anos: com a estatura e influência que seu pensamento logrou, Quijano deverá ser cada vez mais um intelectual analisado, o que o coloca numa situação privilegiada entre seus pares - e não necessariamente confortável. Espera-se que, futuramente, familiares e intelectuais, com respaldo de universidades e editoras, possam organizar um projeto de difusão completa de seus textos. Muitos deles - notadamente os antigos -, são ainda de difícil acesso ao público, editados em revistas peruanas extintas com pequenas tiragens e, atualmente, uma raridade nos sebos de seu próprio país ${ }^{1}$.

Alguns empreendimentos recentes de difusão e circulação da obra quijaneana merecem destaque. $\mathrm{O}$ mais importante deles é a publicação de uma volumosa antologia, intitulada Cuestiones y horizontes. De la dependencia histórico-estrutural a la colonialidad/descolonialidad del poder (Quijano, 2014), pelo Conselho Latino-Americano de Ciências Sociais (CLACSO), organizada e prefaciada pelo brasileiro Danilo Assis Clímaco, em 2014. No mesmo ano, a editora portenha Del Siglo publicou Aníbal Quijano: textos de fundación (Palermo; Quintero, 2014), obra preparada por Zulma Palermo e Pablo Quintero. A análise sobre a trajetória intelectual e política de Quijano é ainda uma agenda de pesquisa novíssima, como se vê no livro organizado por Víctor Hugo Pacheco Chávez, Rompiendo la jaula de la dominación: ensayos en torno a la obra de Aníbal Quijano (Pacheco Chávez, 2018). Publicada no Chile, em meados de 2018, esta coletânea reúne um conjunto de leituras de variados interlocutores da América Latina, especialmente mexicanos e peruanos, em que se acentua

\footnotetext{
${ }^{1}$ Não podemos deixar de mencionar, entretanto, a iniciativa de digitalizar dezenas de textos de Quijano feita pela equipe da Universidad Nacional Autónoma de México (Unam), de Boris Marañón Pimental, disponíveis no blog https://quijanodescolonial.blogspot.com/.
} 
o caráter inovador do arsenal teórico quijaneano, com destaque para a fase da "colonialidade do poder".

Na linha da história das ciências sociais e do marxismo na América Latina, o objetivo deste artigo é, especialmente, reconstruir a trajetória intelectual e política de Aníbal Quijano no contexto de "crise dos paradigmas" das ciências sociais e de declínio da esquerda marxista, que se manifestaram de modo acentuado na década de 1980, e examinar como o sociólogo peruano encontrou soluções diante da encruzilhada histórica que se anunciava a uma geração latino-americana de cientistas sociais engajados. Em seguida, analisa-se o movimento de aproximação e distanciamento que Quijano faz com a tradição marxista, a partir da perspectiva adotada da "colonialidade do poder". Procura-se, assim, observar de que modo o sociólogo peruano foi afetado pelas transformações capitalistas na periferia e pelas derrotas políticas da esquerda tradicional, destacando sua busca por um novo redirecionamento teórico para entender a história da América Latina em sua moldura política e epistêmica. Nesse ínterim, Quijano coloca em curso uma revisão profunda da sociologia marxista e de sua validade, tanto do seu instrumental analítico quanto de seu arsenal político. Nossa hipótese é a de que o marxismo não foi completamente refutado no plano teórico, pois, apesar de Quijano se referir a essa tradição crítica como "uma epistemologia de direita e uma ideologia de esquerda", particularmente em sua face eurocêntrica, ele reivindica paradoxalmente a "racionalidade alternativa" como tributária de Marx e de José Carlos Mariátegui. Já em relação à dimensão política do marxismo, o distanciamento de Quijano parece estar diretamente vinculado ao desgaste sofrido pelas graves derrotas políticas dos movimentos dos trabalhadores na América Latina.

Aníbal Quijano é parte de uma geração de cientistas sociais que não apenas testemunhou as fases de institucionalização da sociologia no continente, especialmente a partir do final da década de 1950, como também acompanhou os encontros e desencontros da sociologia com as sociedades latino-americanas, convulsionadas pelos ciclos da Revolução Cubana de 1959 e pela contrarrevolução chilena em 1973. Ademais, sua 
circulação internacional em diversas universidades da América, como professor e pesquisador visitante, permitiu uma análise diferenciada sobre os descaminhos históricos das ciências sociais na América Latina, das quais ele foi parte integrante e atuante. Portanto, sua análise sociológica sobre a sociologia latino-americana, com especial atenção ao marxismo, não é a de um estudioso distanciado e neutro, mas sim a de um personagem ativo que ajudou a construir um arsenal científico-social em um momento no qual a sociologia foi concebida como uma "ciência de oposição" e "portadora de uma promessa social, a de permitir uma intervenção humana racional em sua própria história" (Quijano, 1981, p. 228). Vale ressaltar ainda, que daremos mais ênfase aos textos de Quijano produzidos na década de 1980, que estão localizados entre a produção marxista-dependentista das décadas de 1960 e 1970, e a teoria da colonialidade do poder das décadas de 1990 e 2000, pois foi justamente nesse período de "crise" que as reflexões sociológicas sobre as formas de conhecimento da sociologia e das derrotas políticas aparecem de modo mais contundente.

Estamos longe de esgotar um assunto cujas informações biográficas e interpretativas ainda estão abertas a modificações e atualizações permanentes. Embora este artigo faça referências aos "grandes textos" produzidos por Quijano, oferece especial atenção aos "textos menores", como os de caráter mais autobiográficos, além de entrevistas concedidas pelo autor na década de 1990 e 2000, pois estes indicam de maneira mais precisa alguns dos delineamentos que buscamos e nem sempre estão presentes nos textos mais sistemáticos de Quijano. Nesse sentido, acreditamos que restaurar discussões geradas por um determinado texto/obra não é apenas permanecer na "estrutura" do pensamento, mas atinar para o processo de sua produção e circulação de ideias. Ao articular elementos biográficos aos contextos políticos de determinado autor, os escritos de ocasião "permitem reconstruir seu ritmo de pensamento e a eficácia de sua intervenção, iluminando, desse modo, as opções teóricas e políticas realizadas pelo autor" (Bianchi, 2014, p. 12). 
Assim, trata-se de romper com a dicotomia entre texto e contexto, "leitura interna" e "leitura externa", em vista da análise da produção intelectual de determinado(s) personagem(ns) e sua(s) obra(s), como se nossa única alternativa metodológica fosse a escolha de um entre esses dois termos. Procura-se, assim, seguir a advertência já feita por Antonio Candido ([1965] 2011) ao produzir entre eles uma síntese, considerando que "a sociologia dos intelectuais também exige que se reconheça e se qualifique a tensão existente entre estes termos, na medida em que ela é constitutiva da própria matéria que cumpre à análise ordenar" (Bastos; Botelho, 2010, p. 913). Isto é, a reconstrução do percurso de um pensamento se faz por meio da investigação sobre a produção de uma obra e o contexto (intelectual ou político) em que a obra foi construída (Bianchi, 2014).

Para evitar mal-entendidos, a relação/tensão entre Quijano e a tradição marxista - tema central neste artigo - será tratada como um movimento de distanciamento e aproximação que se metamorfoseia durante sua trajetória intelectual, especialmente a partir da crítica eurocêntrica. Não se trata, pois, de utilizar um indesejável "marxômetro" (a premissa quimérica da proximidade ou distanciamento daquilo que um determinado autor produz com aquilo que escreveram Marx e Engels dependendo, muitas vezes, da quantidade de suas referências).

Com efeito, essa relação difícil e, muitas vezes, ambígua entre Quijano e a tradição marxista provavelmente fará com que os futuros "porta-vozes" do sociólogo peruano realizem operações arbitrárias para demonstrar resultados antagônicos, a depender do gosto teórico e ideológico dos analistas - ao menos, aqueles apegados à classificação conceitual e à simples rotulação. Afinal, estamos discorrendo sobre um autor que tem acumulado, durante as últimas décadas, "seguidores" de suas ideias - o que constitui, não por coincidência, uma das características típicas que define o processo de consagração de um intelectual. 


\section{O caminho intelectual de Aníbal Quijano: a crítica como vocação}

As antinomias da modernidade na América Latina e as estruturas de poder são a clé de voûte que acompanha toda a jornada intelectual e política de Quijano. Suas primeiras produções nas décadas de 1960 e 1970 foram marcadas pelo ambiente intelectual da capital chilena, polo irradiador transnacional das ciências sociais no continente, em um momento no qual a produção teórica latino-americana se elevou notavelmente (Beigel, 2010). Em Santiago, Quijano vivenciou, transitou e refletiu conjuntamente com personalidades ligadas ao que se convencionou chamar de Teoria da Dependência - uma nova interpretação da inserção e subordinação dos países da periferia capitalista. Ele ocupou o posto de pesquisador do Programa de Investigaciones sobre Urbanización y Marginalidad, na División de Asuntos Sociales, dirigida pelo espanhol José Medina Echavarría da Comissão Econômica para a América Latina (Cepal), entre 1966-1971.

Através da relação entre "centro" e "periferia" e da noção de "dependência estrutural", Quijano procurou repensar criticamente o problema do desenvolvimento como narrativa da modernidade no processo do sistema capitalista periférico (Quintero, 2018). Na contramão das leituras dualistas e evolucionistas da história, que concebiam a passagem linear e homogênea de uma sociedade "tradicional" para uma sociedade "moderna", fortemente presentes nas correntes "modernizadoras" das ciências sociais e nos manuais políticos dos Partidos Comunistas da América Latina, o autor mobilizou a categoria de "heterogeneidade histórico-estrutural" como antídoto, para afirmar que a formação econômico-social peruana estaria articulada por diversas temporalidades históricas. Utilizava, assim, um instrumental teórico semelhante ao de "desenvolvimento desigual e combinado", estilo de análise incorporado por um conjunto de cientistas sociais de sua geração, muitos deles com passagem no Chile, ainda que não se restringisse a esse círculo (como, por exemplo, Francisco de Oliveira, 
no Brasil, e Michael Löwy, na França), em busca de deslindar a reprodução contraditória do capitalismo na periferia (Braga, Rubbo, 2018).

Ao alcançar gradativamente prestígio acadêmico por suas formulações acerca da "marginalização" e suas variantes - urbanização e capitalismo dependente -, além da análise sobre a formação social e cultural do cholo - um capítulo importante para a tradição sociológica no Peru que estava em vias de institucionalização (Navarrete, 2005) -, Quijano inicia também relações com diversos países da América Latina ${ }^{2}$, dentre eles, o Brasil ${ }^{3}$. Já como professor ligado à Universidad Mayor Nacional de San Marcos (UMNSM), teve encontros permanentes e eventuais com cientistas sociais e economistas brasileiros durante sua estada no Chile, como Theotonio dos Santos, Vânia Bambirra, Juarez Brandão Lopes, Fernando Henrique Cardoso e Francisco Weffort. Com este último, inclusive, organizou Populismo, marginalización y dependencia: ensayos de interpretación sociológica, em 1973, publicado na Costa Rica (Weffort; Quijano, 1973). Anos depois, algumas de suas produções que circularam mimeografadas em Santiago foram traduzidas pela primeira vez para o português e organizadas pelo sociólogo e professor da Universidade de São Paulo (USP), Luiz Pereira, com o título de Populações "marginais" (Pereira, 1978) ${ }^{4}$.

\footnotetext{
${ }^{2}$ Trata-se de característica marcante e constante na trajetória acadêmica de Aníbal Quijano, que necessita de maior aprofundamento: o acúmulo de uma rica experiência universitária fora do Peru. Ele foi professor e pesquisador visitante de mais de uma dezena de universidades latino-americanas e europeias.

${ }^{3}$ Ainda não foi realizado um estudo sistemático sobre a relação entre Quijano e o Brasil durante sua larga trajetória. Seria preciso mapear, por exemplo, desde a circulação de Quijano em espaços acadêmicos (universidades, congressos, simpósios, centros etc.) que possibilitou construir vínculos profissionais, políticos e afetivos com pesquisadores brasileiros, às viagens permanentes e ocasionais que realizou ao país, até mecanismos e agentes de difusão de sua produção (tradutores, revistas, coletâneas). Uma de suas mais importantes passagens pelo Brasil, particularmente em São Paulo, foi quando Quijano tornou-se o primeiro titular da cátedra Simón Bolívar, em 1992/1993, por meio de um convênio entre o Instituto de Estudos Avançados (IEA) da USP e o Memorial da América Latina. Para mais informações, ver Zevallos (2018).

${ }^{4}$ No mesmo ano de 1978, publicou-se a coletânea A questão urbana na América Latina, organizada por Fernando Lopes Almeida, com seis ensaios de autores não brasileiros, sendo um deles o artigo Dependência, mudança social e urbanização na América Latina, de Quijano.
} 
Durante suas idas e vindas ao Peru na década de 1970, em conflito permanente com o governo militar de Juan Velasco Alvarado (1968-1975), que resultaria em sua expulsão do país e exílio no México, destino de muitos cientistas sociais da América Latina, Quijano fundou a revista Sociedad y Política (1972-1983). Sem vínculos partidários, a revista converteu-se em um importante espaço de debate da esquerda intelectual peruana e latinoamericana, cujas páginas abrigavam uma variedade tanto de perfis quanto de pontos de vista ${ }^{5}$. Nesse escambo de ideias entre intelectuais e/ou ativistas políticos, Quijano assume uma nova roupagem de intelectual público, escreve uma série de ensaios, com o objetivo de intervir politicamente nas transformações sociais pelas quais a sociedade peruana passava na década de 1970. Mesmo entrincheirado dentro da herança teórica do marxismo revolucionário, sua preocupação em "debater os problemas da revolução socialista do proletariado peruano" não economizou polêmicas com tradições clássicas do marxismo e seus agrupamentos locais (stalinistas, trotskistas, maoístas e althusserianos), tampouco com as vertentes nacionalistas de seu país (aprismo, velasquismo e, mais tarde, o fujimorismo). Inclassificável no próprio "campo" marxista, constatava-se, desde já, uma marca decisiva em seu itinerário político e intelectual: a busca de um pensamento próprio, independente, heterodoxo, sem as amarras doutrinárias e as modas teóricas em voga. Não por acaso, anos depois, com certa ironia, Quijano declaravase como "a minoria de um" (Quijano, 2000b).

Entre os estudos sobre "polo marginal e mão de obra marginal" e as análises do capitalismo periférico atrelado à luta política no Peru, o intelectual nascido em Yanama (província de Yungay, norte do Peru) acompanhou as formas alternativas de participação autogestionária e cogestionária em diversas modalidades organizativas no tecido social, especialmente no mundo marginal urbano, como as Organizaciones Económicas Populares (OEPs), no Chile, e a Comunidad Autogestionaria Villa El Salvador (Cuaves),

${ }^{5}$ É apenas no número 8 da revista Sociedad y Política, em fevereiro de 1980, após dois anos de ausência da revista, que seu editorial anuncia a vinculação do periódico ao Movimiento Revolucionario Socialista (MRS) (Sociedad y Política, 1980, p. 5). 
no Peru - exemplos concretos, segundo ele, de "socialização do poder". Tais fenômenos não eram apenas uma curiosidade sociológica, mas também uma aposta política de Quijano, principalmente nessa última experiência, surgida nos escombros do governo velasquista. A essa altura, ele engajou-se obstinadamente e acompanhou pari passu a trajetória da Cuaves e, em 1976, criou o Movimiento Revolucionario Socialista (MRS), reflexo do ativismo político de sensibilidade libertária que o orientou, consequentemente, em disputas acirradas na esquerda peruana. Trata-se, pois, de pontos decisivos que marcaram a démarche quijaneana na década de 1970.

\section{Melancolia da derrota: sociedade de transição e inflexões teóricas}

As sucessivas derrotas políticas dos movimentos e revoluções sociais no Peru e na América Latina, assim como a crise intelectual e política do marxismo em escala internacional, tiveram um forte impacto na trajetória de Aníbal Quijano em meados da década de 1980. Como afirmou Daniel Bensaïd (2008, p. 10), “a derrota histórica das grandes esperanças do século XX traduzia-se [...] por um estreitamento dos horizontes de esperança e uma retração da temporalidade histórica em torno de um presente empobrecido". Não por acaso, os ensaios do autor peruano produzidos nessa época transitam entre a frustração de não fornecer respostas suficientes às questões do presente, orientado por uma tradição revolucionária explicitamente em crise, e a sensibilidade de repensar as armas da crítica e explorar novas práticas políticas. Assim, marcado pela travessia entre a produção dependentista e marxista da década de 1970 e a "colonialidade do poder" da década de 1990, Quijano produziu questionamentos políticos e epistemológicos sobre tensões subjacentes na história da teoria social latino-americana, particularmente sobre o marxismo.

Nesse momento de reconsiderações e indagações, Quijano iniciou diálogo permanente com um grupo de pesquisadores "marxo-braudelianos", como Immanuel Wallerstein (1930- 2019) e Terence K. Hopkins (1928- 
1997) - cientistas sociais conhecidos por suas análises do "sistema-mundo", impulsionadores do Departamento de Sociologia da Universidade de Bighampton (Nova York-EUA) e da escola de Sociologia Histórica, referências internacionais nas últimas décadas. Para isso, Quijano passa a ocupar o posto de professor em Binghampton desde a década de 1980, integrando-se ao Fernand Braudel Center (fundado e dirigido por Wallerstein) onde lecionaria praticamente um trimestre por ano, segundo informações de Zevallos (2018, p. 426). Decerto, suas preocupações teóricas e metodológicas, na fase da "colonialidade do poder", acerca das múltiplas dimensões da temporalidade em um mesmo processo, da noção de bifurcação como uma totalidade heterogênea e contraditória, bem como da dialética entre "estruturas, conjunturas e cotidiano" na América Latina, são fruto do intercâmbio acadêmico transnacional realizado nos EUA.

Outra experiência acadêmica no exterior ocorreu na região das Antilhas, em 1981, onde Quijano foi professor visitante do Centro de Investigaciones Sociales (CIS) na Universidad de Puerto Rico. No mesmo ano, ele publicou um artigo "Sociedad y sociología en América Latina (Notas para una discussión)", na Revista de Ciencias Sociales, a primeira reflexão mais sistemática sobre o momento de crise atravessado pela sociologia e pela sociedade latinoamericana. Percorrendo o labirinto dos encontros e desencontros entre as fases da sociologia crítica e os problemas político-sociais das sociedades periféricas, Quijano assinalava certo esgotamento do "dependentismo" e do "modo produtivismo", correntes que vigoraram nas ciências sociais nas décadas de 1960 e 1970, sem deixar de reconhecer as duas vertentes como momentos importantes de "refundação efetiva do conhecimento científico-social latino-americano".

No curso daqueles anos, a derrota dos processos "populares" e "revolucionários" trouxe à tona, na realidade e no debate teórico, a maneira pela qual as lutas de classe eram apuradas. Tornou-se necessário, então, e historicamente possível, reunir para a pesquisa as questões que a realidade propunha, em uma teoria desprovida de ambiguidades (Quijano, 1981, p. 236). 
Provavelmente o texto de Quijano mais representativo da experiência internacional descrita acima seja uma conferência apresentada no Seminário CLACSO piensa CLACSO da XII Assembleia Geral Ordinária, em dezembro de 1985, na capital do Uruguai. Pouco lembrado hoje em dia pelos seus leitores, o trabalho tinha como título uma provocativa frase do historiador francês Fernand Braudel: "As ideias são cárceres de larga duração, mas não é indispensável que permaneçamos todo o tempo nesses cárceres". Sua proposta era refletir a "produção" e a "difusão do conhecimento científico social" e sua "relação com poder" nas sociedades latino-americanas. Em um momento de transição histórica, em que a crise dos paradigmas modernos assombrava o campo científico e político, Quijano fez o seguinte testemunho:

Não é verdade que, há dez, quinze anos atrás, grande parte de nós esperávamos que nessa crise ocorresse uma polarização social e política? Sim, e começou a ocorrer. Não posso afirmar que não ocorreu. Mas fomos derrotados. E depois dessa derrota, hoje, podemos apreciar que uma grande parte do rol das ciências sociais e dos cientistas sociais começou a ser definida com uma relação com a pós-crises, a pós-derrota dos movimentos dos dominados em todas as partes (Quijano, 1985, p. 44) ${ }^{6}$.

Como as múltiplas crises (do capitalismo, da modernidade, da democracia) não garantiram um desfecho vitorioso, pelo contrário, deixaram derrotas históricas na memória da esquerda, tornava-se incontornável uma reavaliação estratégica de como entender a história da América Latina, suas origens e sua nova relação com o mundo, em sua moldura política e epistêmica. "A América Latina mudou, e não sabemos porque, pois não a estamos interrogando suficientemente", alertava Quijano (1985, p. 45) no final de sua conferência em Montevidéu. O desencontro histórico entre teoria e realidade latino-americana, marcado pelo fascínio de seus intelectuais e políticos por ideias, noções e teorias europeias, parecia, aos olhos do autor peruano, uma oportunidade propícia para reescrever a história a partir da herança cultural e política existente do mundo não europeu. Tratava-se

${ }^{6}$ Todas as citações de excertos em língua estrangeira foram traduzidas por mim, a quem cabe todas as eventuais inconsistências. 
de ler a América Latina "em função dela mesma; em relação com outras experiências, mas não segundo elas" (Quijano, 1990, p. 12-13, grifos do autor). Desse modo, a experiência das sucessivas derrotas e sua consciência crítica ajudou Quijano a redefinir seu projeto intelectual e político.

Em uma entrevista concedida a Nora Velarde para a revista ILLA - Revista del Centro de Educación y Cultura, publicada em janeiro de 1991, Quijano reforça que a América Latina atravessava um período de "reoriginalização cultural", o que implicava "oportunidades" (e "riscos") para construir uma "racionalidade alternativa" diante da cristalização de um ciclo cumulativo de derrotas. Recusando a velha teleologia marxista dos modos de produção, que garantia um futuro socialista, Quijano reforçou a ideia de que em sociedades periféricas como as da América Latina nada é preestabelecido. Ou seja, eram sociedades de transição e não em transição:

Por que de e não em? Porque é a rejeição à ideia de que algo ocorre entre A e B ou entre $A$ e $Z$, mas que é de transição porque não tem uma dinâmica histórica que leva apenas em uma ou duas direções razoavelmente claras. Ou seja, porque leva, na verdade, em várias e contraditórias direções ao mesmo tempo (Quijano, 1991a, p. 55).

O efeito dessa nova postura intelectual de Quijano possibilitou que o próprio autor refletisse sobre sua trajetória não como uma ruptura total sobre temas e problemas discutidos outrora (emergência do cholo, urbanização, movimentos camponeses, marginalidade), mas levando em conta momentos de continuidades e descontinuidades. Em suas palavras:

Admito que o debate latino-americano dos últimos vinte ou vinte e cinco anos esteve sob o predomínio dos problemas chamados econômicos, sociais e políticos; mas não me parece que os outros problemas tenham estado ausentes desse debate. Primeiro, porque cheguei à conclusão de que, quando a gente fala de ciências sociais, de algum estranho modo, menciona apenas a sociologia, digamos tecnocrática, e a economia e talvez os chamados cientistas políticos. Esquece, no entanto, a antropologia e a história. 
Em seguida, afirma:

Diria, pois, que não sinto que, no movimento de minha reflexão, o cultural tenha estado ausente, nem como tema, nem como questão, embora é certo que, em alguns períodos, pelas características do debate latino-americano, seguramente colocava muito mais ênfase nos outros aspectos (Quijano, 1991a, p. 54-55).

Portanto, o pensamento de Quijano, na década de 1980, era a expressão de uma passagem de dimensões prioritariamente políticas e econômicas para um espaço reflexivo da cultura e da história como mediações fundamentais no novo debate latino-americano que se configurava. Entretanto, apesar das especificidades apontadas em sua trajetória, isso não era algo isolado. As mudanças desencadeadas no capitalismo moderno e seus efeitos na subjetividade - "na noção que as pessoas têm, ou deixam de ter, de si mesmas, e dos problemas de orientação e coordenação do eu dentro desse espaço" - faziam parte de um clima intelectual, naquela época, que repensava paradigmas teóricos discutidos tanto por europeus quanto por estadunidenses. Como resposta principalmente à crise do marxismo, o próprio enfoque na cultura tornou-se de vital importância em uma época de ascensão da política de identidade, do pós-modernismo, do pósestruturalismo e da mídia em geral (Eagleton; Beaumont, 2010, p. 276).

Existiria, pois, algum parentesco entre a virada quijaneana para uma antropologia histórica e cultural e o apogeu das vertentes pós-modernas? A construção da teoria da colonialidade não se submeteu, afinal, à "desconfiança em relação aos entusiasmos volúveis e aos efeitos de moda [que] exige sérias refutações de se pôr em questão um paradigma futuro" (Bensaïd, 2008, p. 22)? É preciso ressaltar, primeiramente, que o estilo da escrita de Quijano sempre foi econômico em citações de autores, escolas e tendências, assinalado por elevada generalidade, dificultando um possível mapeamento de suas afinidades negativas e eletivas no campo das ciências sociais estrangeiras. Não há registros, por exemplo, sobre Baudrillard, Lyotard, Derrida, Foucault, Berman, Said, Williams, Harvey, Jameson, 
Spivak, Eagleton etc., autores que paulatinamente ganhavam notoriedade nas ciências humanas da América Latina.

Todavia, em um pequeno trecho de Modernidad, identidad y utopía en América Latina, de 1988, Quijano menciona o debate europeu sobre modernidade e pós-modernidade e o estadunidense sobre antimodernidade da seguinte maneira:

O problema, não obstante, é que os profetas da "pós-modernidade" e da antimodernidade não somente nos convidam a celebrar os funerais das promessas liberadoras da razão histórica e de sua específica modernidade, mas principalmente a nunca mais considerar questões implicadas nessa modernidade, não voltar à luta pela liberação da sociedade contra o poder e aceitar no futuro unicamente a lógica da tecnologia e do discurso do poder (Quijano, 1988, p. 20).

Ora, para o autor, a crítica da modernidade na América Latina não implicava uma negação da "razão histórica", e sim a superação da "razão instrumental". A primeira encarnava uma razão construída pelo ideário da "libertação", enquanto a segunda gestou-se no "utilitarismo" e no exercício da "dominação". Inspirada na tradição frankfurtiana, essa distinção das razões (histórica versus instrumental) é fundamental para entender a crítica ao eurocentrismo de Quijano, que, naquele momento, não se confundiu com um antieuropeísmo - como acontece com os estudos pós(-)coloniais, os quais exercem, atualmente, a hegemonia da crítica epistemológica à dominação europeia-ocidental sobre outras civilizações ${ }^{7}$.

A refutação explícita é à "colonialidade de poder" - termo que aparece pela primeira vez no artigo Colonialidad y modernidad/racionalidad, na revista Perú Indígena (Quijano, 1992a) - enquanto produção de um desencontro entre experiência histórica latino-americana e a ideia europeia ocidental de conhecimento universal. Para Quijano, a percepção de sujeito e objeto como duas entidades independentes entre si, a relação entre causa e efeito como uma sequência linear, a oposição entre logos e mito seriam categorias

${ }^{7}$ Um interessante debate sobre o surgimento de diferenças entre as vertentes que encampam a denominação de "pós(-)colonial" pode ser consultado em Braga e Cahen (2018). 
separadas "arbitrariamente" pela "racionalidade-modernidade-europeia"; em suma, para ficar na metáfora quijaneana, uma cisão entre "árvore do conhecimento e árvore da vida".

Sua explicação filosófica de uma "racionalidade alternativa" - termo que aparece pela primeira vez em Modernidad, identidad y utopía en América Latina (Quijano, 1988) -, a partir das condições históricas do continente, basear-se-ia na ênfase da "heterogeneidade histórica-estrutural" e na busca "de todo exercício de identidade histórica autônoma" (Quijano, 1992b, p. 79). Na elaboração de uma "teoria" de longue durée, Quijano ressalta um novo sistema de dominação social produzido para dar inteligibilidade histórica às novas relações de poder constituídas desde o "descobrimento", em 1492: a raça. Produto e fundamento do eurocentrismo na América Latina, a noção de raça revelar-se-ia não apenas na acumulação originária do capital do sistema-mundo, mas sob uma "classificação social" fundada no "controle do trabalho" e em dispositivos "intersubjetivos", que produziu identidades sociais novas: índios, negros, amarelos e mestiços. Nesse "padrão de poder" constituído, o capitalismo moderno/colonial forjou uma "concepção de humanidade segundo a qual a população do mundo se diferenciava em inferiores e superiores, irracionais e racionais, primitivos e civilizados, tradicionais e modernos" (Quijano, [2000] 2010, p. 86).

\section{Encruzilhadas eurocêntricas: herança marxista e o espectro de Mariátegui}

A "colonialidade do poder" tornou-se, portanto, uma nova metanarrativa caracterizada por uma "teoria histórica da classificação social" e da "divisão racial do trabalho". A consciência da derrota fez com que Quijano realizasse um acerto de contas com a tradição marxista, a qual moldara, em grande medida, suas análises sociológicas e políticas. Na conferência para a CLACSO em Montevidéu, a crítica à tradição marxista já se fazia presente quando o sociólogo peruano, tomando a expressão de Francisco de Oliveira de "vulgata marxista", assinalou que a influência positivista e mecanicista no marxismo 
assombrava as ciências sociais no continente. Na realidade, esse tipo de crítica não era propriamente uma novidade para quem esteve em torno da tradição dependentista e sempre havia lutado contra o stalinismo, não nas fileiras do trotskismo - cuja aproximação na juventude fora efêmera e frustrante (Quijano, 1991c) -, mas forjada no campo político de movimentos sociais com perfil de autogestão que entravam em cena na década anterior. De qualquer forma, nem mesmo o marxismo crítico saiu ileso do sentimento de uma derrota história da esquerda e do movimento dos trabalhadores (Palti, 2010).

Nessa nova etapa de sua trajetória intelectual, o autor de El fujimorismo y el Peru parece não se identificar mais como um intelectual marxista, o que ocorria explicitamente durante a década de 1960 e $1970^{8}$. Mas isso não o inibiu de continuar a travar diálogos com uma tradição intelectual que não se apagava tão facilmente do capital acumulado em sua formação teórica e política. Mais do que isso, não o impediu de utilizar algumas ferramentas analíticas marxistas à luz da construção da teoria da colonialidade, das análises de conjuntura econômica e política sobre o capitalismo na América Latina e da emergência dos movimentos sociais nas décadas de 1990 e 2000. A mais famosa delas é a proposta teórica do "moderno sistema-mundo" de Immanuel Wallerstein que, segundo o próprio Quijano, deságua na "visão marxiana do capitalismo como um sistema mundial e braudeliana sobre a longa duração histórica, [que] reabriu e renovou de modo decisivo o debate sobre a reconstituição de uma perspectiva global, na pesquisa científicosocial do último quartel do século XX" (Quijano, [2000] 2010, p. 87). De caráter "interdisciplinar", a perspectiva do "moderno sistema-mundo" seria uma contribuição teórica e histórica sobre o poder contemporâneo e, também, uma "recuperação de uma parte central de Marx", especialmente das noções de "descobrimento do caráter mundial do capitalismo" e da

${ }^{8} \mathrm{Um}$ indício do distanciamento de Quijano do marxismo pode ser aferido em um depoimento de Michael Löwy para a pesquisa que originou este artigo. Em um dos Fóruns Sociais Mundiais de Porto Alegre, Löwy convidou o sociólogo peruano - que recusou - para fazer parte de uma nova reedição da antologia O marxismo na América Latina, publicada em francês em 1980 (em espanhol em 1982 e em português em 1999). Lembrando que na primeira edição Quijano contribuíra com o artigo Caractère et perspective de l'actuel régime militaire au Perou (Michael Löwy, entrevista com Deni Alfaro Rubbo, agosto de 2017). 
"perspectiva epistêmica da totalidade histórica necessariamente implicada no conhecimento" (Quijano, 2004b, p. 176). Isso foi motivo, inclusive, para que escrevesse um texto em conjunto com o sociólogo nova-iorquino sobre a relação entre a América e a nova configuração capitalista em curso (Quijano; Wallerstein, 1992, p. 583-591)9.

Nota-se que o sociólogo peruano não realizou um estudo independente sobre Marx e o marxismo. Contudo, seus ensaios mais sistemáticos La nueva heterogeneidad estructural de America Latina (Quijano, 1990), publicado na revista limenha Hueso Humero, e Colonialidad del poder y classificación social (Quijano, 2000a), publicado na revista estadunidense Journal WorldSystems Research, escritos em um intervalo de dez anos, são momentos privilegiados em que a tradição marxista é retomada e confrontada de maneira mais explícita.

Na realidade, Quijano decidiu abordar a tradição marxista de maneira crítica com uma história feita de tensões e contradições, o que, por sua vez, desembocou em uma "heterogênea herança" de Marx (Quijano, [2000] 2010, p. 89) ${ }^{\mathbf{1 0}}$. O particular confronto foi com a versão marxista do "materialismo histórico", moldada pela visão de acumulação quantitativa das forças produtivas; pelas relações entre os componentes de uma estrutura societal (relações de produção) vistas como "dadas, a-históricas"; "por uma estrutura configurada por elementos historicamente homogêneos", lineares e unidirecionais. Essa versão eurocêntrica seria representada pela "hibridização marxo-positivista", do "último" Engels aos teóricos da social-

${ }^{9} \mathrm{O}$ pesquisador francês Michel Cahen, embora tenha algumas ressalvas ao empreendimento teórico de Quijano, reconhece que "o conceito de colonialidade permite pensar as sociedades na sua globalidade e não como justaposição de comunidades e fragmentos, e pode permitir pensar de uma maneira nova os estados no seu relacionamento com o sistema-mundo e na longa duração" (Cahen, 2018, p. 42).

${ }^{10} \mathrm{Em}$ uma entrevista em 2000, Quijano volta a discorrer sobre a tradição marxista e afirma que "Marx foi extremamente heterogêneo e, para mim, por certo, felizmente". Para o autor, a perspectiva de Marx "era basicamente eurocêntrica", embora "ele jamais fosse prisioneiro do eurocentrismo". Questionado pelos entrevistadores por uma visão demasiada monolítica do marxismo, Quijano insiste que Marx não criou uma "doutrina", mas um esforço teórico contraditório e conflitante e, portanto, via como ineficaz deduzir um modelo de suas formulações. A afirmação de vertentes dominantes de cunho positivista - "o materialismo histórico" - não significa uma tradição homogênea e sim que uma vertente hegemônica subordina outras, sendo estas marginalizadas (Quijano, 2000b, p. 7-8). 
democracia europeia, passando pelo "marxismo-leninismo" - imposto pelo "despotismo burocrático" stalinista - e, finalmente, pelo estruturalismo francês representado por Louis Althusser (Quijano, 2010, p. 101). Por se tratar de um acerto de contas com uma tradição à qual esteve historicamente atrelado dentro de um segmento, Quijano parece mais preocupado em desconstruir (ou "descolonizar") tais visões de mundo modernas, dirigindo-se muito mais contra o eurocentrismo da esquerda marxista do que contra a direita eurocêntrica liberal, que leram a América Latina "como-se-fosseEuropa” (Quijano, 1990, p. 12). Seja como for, os dois artigos assinalados não oferecem indícios de qualquer intenção em estabelecer uma disputa intelectual e política em torno da tradição hegemônica marxista do século $X X$, o que distanciaria o autor de uma identidade intelectual marxista.

Por um lado, há um consenso de que a linha marxista ortodoxa foi constituída por uma apologia indiscriminada ao paradigma europeu ocidental, em todas as suas formas (social, política, econômica, cultural e epistemológica). Por outro, não é menos verdadeiro que, no interior da tradição marxista, há aqueles (como os autores ligados à Escola de Frankfurt) que produziram uma "dialética da modernidade" cujo pressuposto reside em um olhar do lado "obscuro" da modernidade e da crítica abstrata do progresso. Sendo assim, poder-se-ia aventar uma possível afinidade eletiva entre a crítica marxista e a teoria da colonialidade. Enquanto a vertente "decolonial" enfatiza as consequências epistemológicas e culturais, o marxismo sublinhou, principalmente, a dimensão econômico-social; de todo modo, ambos buscam, cada qual a seu modo, explicitar os "cadáveres" produzidos pela modernidade ocidental capitalista ${ }^{11}$.

A ausência de diálogo de Quijano com o renascimento do marxismo acadêmico e político de meados da década de 1990 registra seu afastamento

\footnotetext{
${ }^{11}$ Como afirma o marxista sueco Göran Therborn (2012, p. 61): "Simultaneamente, o marxismo afirmou as características positivas e progressistas do capitalismo, como a industrialização, a urbanização, a alfabetização das massas, o olhar para o futuro ao invés de para o passado e manter os olhos fixos no presente; por outro lado, denunciou a exploração, alienação humana, a mercadorização e a instrumentalização do social, a falsa ideologia e o imperialismo inerentes ao processo de modernização".
} 
de uma identidade enquanto "sociólogo marxista" e/ou "marxista latinoamericano". Era um contexto de renovação dos movimentos sociais na França marcada pelo retorno da "questão social" (Braga, 2009, p. 81-82). A "volta a Marx" inicia-se com o trabalho editorial como Actuel Marx, Futur Antérieur e, mais tarde, Contretemps, e a iniciativa de autores do pósestruturalismo reivindicando Marx, como Jaques Derrida em seu Espectros de Marx, ou pela intenção declarada de Gilles Deleuze de consagrar um livro "ao grande Karl" (Bensaïd, 2013, p. 171). Além da publicação de livros como Convoiter l'impossible: I'utopie avec Marx, malgré Marx de Henri Maler e Marx I'intempestif: grandeurs et misères d'une aventure critique, XIXe-XXe siécles, de Daniel Bensaïd, cuja intenção era reler Marx numa chave antideterminista, defendendo uma visão da história enquanto "processo aberto, com bifurcações e encruzilhadas" (Löwy, 2000, p. 253). Como assinala André Tosel, a emergência dos "mil marxismos" em programas de pesquisas no pós-Guerra Fria, especialmente na França e na Itália, reacendeu uma discussão crítica do marxismo em busca de novas descobertas, inversões e matizes, a partir da leitura dos "grandes hereges" que, durante o século XX, foram ocultados pelo marxismo de Estado. Figuras como Ernst Bloch, Jean-Paul Sartre, Walter Benjamin, Lucien Goldmann, Louis Althusser, Henri Lefebvre, Ernest Mandel e outros ressurgem no horizonte da história intelectual do marxismo acadêmico. Assim, "desejada por muito tempo, contra a violência do partido-Estado, essa pluralidade torna disponível Marx e os marxismos" (Tosel, 2009, p.79).

De certa forma, embora tenha uma relação ambígua com o marxismo, Quijano pode ser visto também como parte integrante de uma época de reconstrução e surgimento dos "mil marxismos" - nesse caso, como um dos representantes latino-americanos, ao lado especialmente de Enrique Dussel, que estudará o "último" Marx na década de 1980. Para tanto, a chave dessa hipótese está na relação estabelecida por Quijano com um pensador marxista latino-americano "herege" do século XX: José Carlos Mariátegui. Com efeito, a obra mariateguiana na sociologia de Quijano passou por apropriações diferentes, de acordo com o momento da trajetória intelectual adotada 
pelo autor (Rubbo, 2018a). Se, durante a década de 1970, Quijano foi um leitor marxista de Mariátegui, interessado principalmente em reinstaurar um Mariátegui "autêntico", contra "deformações" e "falsificações" acumuladas pela esquerda peruana, na década de 1990 o eixo interpretativo modificouse significativamente.

Entre o colapso da União Soviética e o centenário do nascimento de Mariátegui (em 1994), Quijano produziu uma série de textos acadêmicos e jornalísticos e participou de eventos que promoveram o homenageado, hoje canonizado pela cultura peruana (Quijano, 1991b; 1993c; 1994a; 1994b; 1994c; 1995). Apesar de seu conhecimento erudito, ratificado em seu trabalho para a editora venezuelana Biblioteca Ayacucho, em 1979 (Quijano, 1979), sua contribuição não foi mais uma exegese sobre Mariátegui ou uma contextualização política e econômica dos anos de formação do Amauta. Em uma entrevista concedida à revista peruana Cuestión del Estado, em 1994, ao lado do teólogo Gustavo Gutiérrez, Quijano afirmava que um dos méritos de Mariátegui consistia em sua "autonomia e liberdade intelectual", não apenas como uma virtude pessoal, mas fundamentalmente pelo engajamento de uma "nova maneira de conhecer" a realidade peruana, sob uma "postura teórica" e uma "proposta política socialista" (Gutiérrez; Quijano, 1994, p. 41). A seus olhos, Mariátegui foi quem iniciou na América Latina um acerto de contas com a herança eurocêntrica do seu tempo, embora não tenha desenvolvido de uma maneira "consciente e sistemática", registrava uma passagem para uma nova "perspectiva cognitiva"12.

Nessa época, outra entrevista concedida por Quijano a Roland Forgues, publicada em 1993, ilumina com mais precisão o "nó marxista" que, para ele, estava em questão:

O problema não é defender um marxismo frente a outro, mas ver de que modo é possível repensar um assunto pendente. Na América Latina deve-se voltar a emoldurar uma frase de Mariátegui: "[n]a América Latina na luta entre exploradores e explorados não nos ocorre segmentar". A exploração e

12Para mais detalhes acerca da apropriação de Quijano em Mariátegui, ver Montoya Huamaní (2018) e Rubbo (2018a; 2018b). 
a dominação, não somente não desapareceram, modificaram-se e assumiram outras formas com outros sujeitos sociais. De modo que, em cada condição específica, esse problema se coloca de maneira distinta. E a luta não pode ser somente contra um dominador A a favor de um dominador B. É contra toda exploração e contra toda dominação (Quijano, 1993a, p. 306, grifos acrescidos).

Logo após, faz a seguinte pergunta:

O que estou pontuando em nossa conversa é um assunto crucial: o que nos levou, durantes tantas décadas, à obsessão de determinar que classe de instituição política é mais eficaz para capturar o poder, ou seja, esse Estado, e fabricar uma sociedade? Não é isso que Marx queria trabalhar (Quijano, 1993a, p. 307).

Em El marxismo de Mariátegui: una propuesta de racionalidad alternativa, Quijano afirmou que o primeiro pensador "em direção a uma racionalidade alternativa que se constituiu na entrada da modernidade" foi... Marx. Mais do que qualquer outra produção do sociólogo peruano, é nesse ensaio que encontramos a ponte entre Marx, Mariátegui e "racionalidade alternativa" como uma forma de atualização da crítica marxista da modernidade. Embora não tenha dialogado com a produção marxista francesa sobre Marx que surgia naqueles anos, talvez pela opção de não entrar na peleja "marxismo ortodoxo versus marxismo heterodoxo", Quijano reforçava que as propostas do autor de O Capital "voltaram de todos os modos ao primeiro plano do debate que se tem aberto com a crise da modernidade". E concluía que "nelas [as propostas de Marx] o conhecimento é um produto históricosocial, ou seja, sempre referido a um universo intersubjetivo, historicamente constituído, e é parte de um complexo no qual está associado à ação e à transformação" (Quijano, 1995, p. 42).

Foi nesse "novo" Mariátegui (e, em menor grau, Marx) que Quijano procurou inspiração intelectual e política para seu empreendimento. Contudo, não podemos diminuir a importância da própria tradição intelectual de que o sociólogo peruano fez parte nas décadas de 1960 e 1970: cientistas sociais latino-americanos - de um modo geral identificados 
com o marxismo - os quais, a partir das noções de "heterogeneidade estrutural" e de "dependência", encetaram uma análise alternativa ao "dualismo", pedra angular da teoria da "modernização". Ademais, a literatura latino-americana (de José María Arguedas a Julio Cortázar, passando por Juan Rulfo e Gabriel García Márquez), florescida principalmente entre as décadas de 1960 e 1980, também tem seu lugar cativo na genealogia intelectual que influenciou Aníbal Quijano.

\section{Utopias latino-americanas: entre a sociologia na derrota e a sociologia da esperança}

Outro fato importante é que Quijano integrou-se ao Grupo Modernidade/ Colonialidade $(\mathrm{M} / \mathrm{C})$ ou "programa de investigação de modernidade/ colonialidade", fundado em 1996 por uma recente geração de pesquisadores de universidades estadunidenses e latino-americanas, além dele próprio, do argentino radicado no México, Enrique Dussel (nascido em 1934), e também do argentino Walter Mignolo (nascido em 1941) ${ }^{13}$. Rapidamente, os estudos elaborados por Quijano, que questionam a "colonialidade do poder", e implicam uma crítica radical ao eurocentrismo no modo de produção e no controle da subjetividade, formaram a base epistemológica comum da equipe de docentes e pesquisadores do $\mathrm{M} / \mathrm{C}$. A criação dessa ampla agenda de pesquisa explica, em grande parte, a audiência, a projeção e a circulação transnacional da teoria da colonialidade, principalmente nas universidades latino-americanas, com especial impacto nos estudos culturais sobre raça, gênero e movimentos sociais.

Em meio às transformações econômicas, sociais e políticas na América Latina durante as décadas de 1990 e 2000, marcadas pela "onda neoliberal", Quijano acompanhou a formação de novos sujeitos sociais e suas novas reivindicações, como o Movimento dos Trabalhadores Sem Terra (MST) no Brasil, os piqueteros na Argentina e os movimentos indígenas no Equador, Bolívia e México. Para o autor, tais movimentos sociais representavam modelos do "processo de nova subjetivação social", muitos deles organizados

${ }^{13}$ Para uma análise sobre a história do M/C, ver Ballestrin (2013) e Escobar (2003). 
como núcleos de produção orientados pela "reciprocidade" e por redes de produção autogeridas e de autogoverno de tipo comunal para a ocupação e a gestão de terras e de fábricas abandonadas (Quijano, 2004a, p. 148-152).

Não custa recordar que Quijano talhou a noção de "reciprocidade" como uma nova forma societal ainda na década de 1970, inspirado nas tradições comunitárias do campesinato indígena e nos movimentos de ocupação urbana. Analisando a categoria no conjunto de sua obra, López Córdova (2018, p. 188) assevera que, em um primeiro momento, a definição de "reciprocidade" estava circunscrita a um aspecto econômico - "intercâmbio" e "força de trabalho". Entretanto, em seus trabalhos posteriores, a noção foi ampliada como uma nova subjetividade que "produz sentidos ou perspectivas mentais diferentes das do capitalismo, isto é, um imaginário anticapitalista". Em busca de "economias alternativas", de instituições/organizações de "democracia direta", Quijano trouxe também noções como as de "trabalho coletivo", "solidariedade" e "comunidade", que seriam formas de "autoridade coletiva" no âmbito das instituições comunitárias, um conjunto de "práticas sociais que reatualizam e que surgem como resultado das tendências do capital” (López Córdova, 2018, p. 201).

Nesse sentido, existe um forte espírito utópico que acompanha o itinerário de Quijano em busca de uma "autêntica comunidade humana". A idealização das "práticas anticapitalistas" e da "democratização da vida cotidiana" dos movimentos sociais é uma espécie de reservatório utópico do autor, que permanece fortemente enraizado em seu horizonte intelectual e político como uma profissão de fé inabalável. Em um texto e entrevista para revista bilíngue Nossa América do Memorial da América Latina de São Paulo, em 1993, no período que estava ligado ao Instituto de Estudos Avançados da USP, Quijano afirmava a utopia como projeção de sonhos e "esperanças dos dominados". Ela tinha o potencial de uma "estética subversiva", de outro imaginário do mundo, como parte da estrutura de relações intersubjetivas "contra toda forma de exploração" (Quijano, 1993b, p. 95).

Portanto, as análises de Quijano orientadas pela perspectiva da descolonização do poder não são apenas uma crítica meramente 
epistemológica: elas estão ligadas às definições estratégicas de lutas políticas e às formas de atuação engendradas pela emergência dos movimentos sociais latino-americanos nas décadas de 1990 e 2000 (o que não é garantia de condescendência crítica). A construção desse arsenal teórico também está ancorada na inflexão histórica que atravessou a geração de Quijano, diante de uma transição do "princípio da esperança" para o "princípio da responsabilidade", como afirma Enzo Traverso (2018, p. 38), inspirado em Ernst Bloch. Os "tempos de derrotas", marcados pelo eclipse de intelectuais engajados, principalmente na década de 1990, impulsionaram, aos olhos do autor, uma mutação no "padrão de memória", acompanhada pela crise de "identidade social e política" (Quijano, 2000b, p. 11). Diante das experiências traumáticas do "socialismo realmente existente", era necessário que a palavra revolução fosse "expressão de outro imaginário social" como "a possibilidade da produção democrática de uma sociedade democrática" (Quijano, 2009, p. 39).

As formulações da "colonialidade de poder" traçadas por Quijano não podem ser confundidas com aquelas de seus seguidores que se apropriam de diferentes modos para finalidades diversas. O exemplo mais evidente são os trabalhos de Walter Mignolo com uma "leitura pouco indutiva de práticas, experiências e realidades sociais que não são estudadas com uma profundidade adequada, mas são utilizadas e (ou) reapropriadas para justificações epistemológicas mais amplas" (Bringel; Domingues, 2015, p. 60). Ou, como provocativamente assinala Browitt (2014, p. 27-28), no afã de evitar dualismos culturais e ideológicos eurocêntricos, o discurso dos decoloniais latino-americanos, baseado também na noção de "diferença colonial", faz, muitas vezes, uma interpretação "estática" e "redutora" da Europa, do Ocidente, da Modernidade em uma espécie de dualidade às avessas.

Esse terreno pantanoso, ainda em disputa, é mais um motivo para continuar pesquisas, debates e provocações sobre a sociologia da esperança e da mudança social de Aníbal Quijano. Seus mais de cinquenta anos de contribuição para ciências sociais têm, cada vez mais, atravessado fronteiras e utopias. 
Deni Ireneu Alfaro Rubbo é mestre e doutor em Sociologia pela Universidade de São Paulo e professor adjunto de Sociologia na Universidade Estadual do Mato Grosso do Sul.

ఏdeni_out27@uol.com.br

\section{Referências}

1. ALMEIDA, Fernando L. (org). A questão urbana na América Latina. Rio de Janeiro: Forense-Universitária, 1978.

2. BALLESTRIN, Luciana. América Latina e o giro decolonial. Revista Brasileira de Ciência Política, Brasília, n.11, p. 89-117, 2013. doi: 10.1590/S010333522013000200004

3. BASTOS, Élide R.; BOTELHO, André. Para uma sociologia dos intelectuais. Dados - Revista de Ciências Sociais, Rio de Janeiro, v. 53, n. 4, 2010. doi: 10.1590/S0011-52582010000400004

4. BEIGEL, Fernanda. Dependency analysis: the creation of new social theory in Latin America. In: PATEL, Sujata (Ed.). The ISA handbook of diverse sociological traditions. London: Sage, 2010, p. 189-200. doi: 10.4135/9781446221396.n15

5. BENSAÏD, Daniel. Marx, manual de instruções. São Paulo: Boitempo, 2013.

6. BENSAIID, Daniel. Os irredutíveis: teoremas da resistência para o tempo presente. São Paulo: Boitempo, 2008.

7. BIANCHI, Álvaro. Para uma história política do pensamento político: anotações preliminares. GPMPP Working Papers, Campinas, n. 1, 2014.

8. BRAGA, Ruy. O pêndulo de Marx: sociologias públicas e engajamento social. In: BRAGA, Ruy; BURAWOY, Michael. Por uma sociologia pública. São Paulo: Alameda, 2009, p. 67-116.

9. BRAGA, Ruy; CAHEN, Michel. Anticolonial, pós(-)colonial, decolonial: e depois? In: BRAGA, Ruy; CAHEN, Michel (Orgs.). Para além do pós (-) colonial. São Paulo: Alameda, 2018, p. 9-31.

10. BRAGA, Ruy; RUBBO, Deni A. Dois mestres na periferia do capitalismo: Michael Löwy e Mariátegui. Cadernos CRH, Salvador, v. 31, n. 83, p. 321-334, 2018. doi: 10.1590/s0103-49792018000200010

11. BRINGEL, Breno; DOMINGUES, José M. Teoria social, extroversão e autonomia: impasses e horizontes da sociologia (semi)periférica contemporânea. Cadernos CRH, Salvador, v. 28, n. 73, p. 59-76, 2015. doi: 10.1590/S010349792015000100005.

12. BROWITT, Jeff. La teoría decolonial: buscando la identidad en el mercado académico. Cuadernos de Literatura. Bogotá, v. 18, n. 36, p. 25-36, 2014. doi: 10.11144/Javeriana.CL18-36.tdbi

13. CAHEN, Michel. O que pode ser e o que não pode ser a colonialidade: para uma aproximação "pós-póscolonial" da subalternidade. In: BRAGA, Ruy; CAHEN, 
Michel (Orgs.) Para além do pós (-) colonial. São Paulo: Boitempo, 2018, p. 31 73.

14. CANDIDO, Antonio. Crítica e sociologia. In: CANDIDO, Antonio. Literatura e sociedade. 12a edição. Rio de Janeiro: Ouro Sobre Azul, [1965] 2011.

15. EAGLETON, Terry; BEAUMONT, Matthew. A tarefa do crítico. São Paulo: Editora Unesp, 2010.

16. ESCOBAR, Arturo. Mundos y conocimiento de otro modo: el programa de investigación modernidad/colonialidad. Tabula Rasa, Bogota (Colômbia), n.1, p. 58-86, 2003. http://www.redalyc.org/articulo.oa?id=396/39600104

17. GUTIÉRREZ, Gustavo; QUIJANO, Aníbal. Mariátegui contra la expropiación de la utopía. Cuestión de Estado. Lima, ano 2, n. 8-9, p. 37 ss.,1994.

18. LÓPEZ CÓRDOVA, Dania. El lugar de la reciprocidad en el pensamiento de Aníbal Quijano. In: PACHECO CHÁVEZ, Victor H. (Org.). Rompiendo la jaula de la dominación: ensayos en torno a la obra de Aníbal Quijano. Santiago: Doble Ciencia Editorial, 2018, p. 163-204.

19. LÖWY, Michael. Luta anticapitalista e renovação do marxismo: entrevista com Michael Löwy. In: LÖWY, Michael; BENSAÏD, Daniel. Marxismo, modernidade e utopia. São Paulo: Xamã, 2000.

20. MONTOYA HUAMANI, Segundo. Aníbal Quijano: improntas de Mariátegui en la colonialidad del poder. In: MONTOYA HUAMANI, Segundo. Conflictos de interpretación en torno al marxismo de Mariátegui. Lima: Heraldos Editores, 2018.

21. NAVARRETE, Julio Mejia. El desarrollo de la sociología en el Perú: notas introductorias. Sociologias, Porto Alegre, n. 14, p. 302-337, dez. 2005. doi: 10.1590/S1517-45222005000200012

22. PACHECO CHÁVEZ, Victor H. (Org.) Rompiendo la jaula de la dominación: ensayos en torno a la obra de Aníbal Quijano. Santiago: Doble Ciencia Editorial, 2018.

23. PALERMO, Zulma; QUINTERO, Pablo (Orgs.). Aníbal Quijano: textos de fundación. Buenos Aires: Del Siglo, 2014.

24. PALTI, Elías José. Verdade y saberes del marxismo: reacciones de una tradición política ante su "crisis". Buenos Aires: Fondo de Cultura Económica, 2010.

25. PEREIRA, Luiz (Org.). Populações "marginais". São Paulo: Duas Cidades, 1978.

26. QUIJANO, Aníbal. Prólogo. In: MARIÁTEGUI, José C. Siete ensayos de interpretación de la realidad peruana. Caracas: Biblioteca Ayacucho, 1979.

27. QUIJANO, Aníbal. Sociedad y sociología en América Latina. Revista de Ciencias Sociales. Porto Rico, v. 23, n. 1-2, p. 223-249, 1981.

28. QUIJANO, Aníbal. Las ideas son cárceles de larga duración, pero no es indispensable que permanezcamos todo el tiempo en esas cárceles. David y 
Goliath. Buenos Aires, Consejo Latinoamericano de Ciencias Sociales (CLACSO), v. 16, n. 49, jul. 1985.

29. QUIJANO, Aníbal. Modernidad, identidad y utopia en America Latina. Lima: Sociedad y Política, 1988.

30. QUIJANO, Aníbal. La nueva heterogeneidad estructural de America Latina. Hueso Humero, Lima, n. 26, p. 8-33, 1990.

31. QUIJANO, Aníbal. La modernidad, el capital y América Latina nacieron en el mismo día. Entrevista de Nora Velarde. ILLA, Revista del Centro de Educación y Cultura, n. 10, jan., p. 42-57, 1991a.

32. QUIJANO, Aníbal (Ed.). Prólogo. In: MARIÁTEGUI, José C. Textos basicos (Seleção, introdução e prólogos de cada seção, de Aníbal Quijano). México-Lima: Fondo de Cultura Económica, 1991b.

33. QUIJANO, Aníbal. Trotsky (entre paréntesis). Sí. Lima, n. 64, jul. 1991c.

34. QUIJANO, Aníbal. Colonialidad y modernidad/racionalidad. Perú Indígena, Lima, v. 13, n. 29, p.11-20, 1992a.

35. QUIJANO, Aníbal. Notas sobre a questão da identidade e nação no Peru. Estudos Avançados, IEA-USP, v. 6, n. 16, São Paulo, p. 73-80, 1992b. doi: 10.1590/S0103-40141992000300007

36. QUIJANO, Aníbal. El tiempo de la agonía. Entrevista. In: FORGUES, Roland. (Org.). Perú, entre el desafío de la violencia y el sueño de lo posible. Lima: Minerva, 1993a, p. 287-309.

37. QUIJANO, Aníbal. Estetica de la utopia. Entrevista de Carlos Moraes e Regina Porto. Nossa América. São Paulo, v. 3, n. 1, p. 92-99, 1993 b.

38. QUIJANO, Aníbal. Raza, etnia y nación en Mariátegui: cuestiones abiertas. In: Encuentro Internacional - José Carlos Mariátegui y Europa: el otro aspecto del descubrimiento. Lima: Amauta, 1993c, p. 167-188.

39. QUIJANO, Aníbal. El gato y su sonrisa en el país de las maravillas. ¿Qué celebramos en el centenario de José Carlos Mariátegui? Que hacer. Revista del Centro de Estudios y Promoción del Desarollo. Lima: DESCO, Lima, n. 89, 1994 a.

40. QUIJANO, Aníbal. El precio de la racionalidad. Gaceta Sanmarquina. Lima, Universidad de San Marcos, v. 5, n. 22, p. 4, 1994 b.

41. QUIJANO, Aníbal. El sueño dogmático. In: FERNÁNDEZ DÍAZ, Osvaldo. Mariátegui o la experiencia del otro. Lima: Amauta, 1994c, p. XI-XV.

42. QUIJANO, Aníbal. El marxismo en Mariátegui: una propuesta de racionalidad alternativa. In: SOBREVILLA, David (Org.). El marxismo de Mariátegui. Seminario del V Congreso Nacional de Filosofía. Lima: Amauta, 1995.

43. QUIJANO, Aníbal. Colonialidad del poder y classificación social. Journal of World-Systems Research, v. 6, n. 2, p. 342-386, 2000 a.

44. QUIJANO, Aníbal. El intelectual frente al pensamiento único: una entrevista con Aníbal Quijano, de Carlos I. Degregori y Carlos Reyna. Que hacer. Revista 
del Centro de Estudios y Promoción del Desarollo. Lima: DESCO, jul.-ago. 2000b, p. 6-16.

45. QUIJANO, Aníbal. O labirinto da América Latina: existem outras saídas? In: MARTINS, Carlos E.; SÁ, Fernando; BRUCKMANN, Mónica (Orgs.). Globalização: dimensões e alternativas. Rio de Janeiro: Loyola, 2004a, p. 142-173.

46. QUIJANO, Aníbal. Immanuel Wallerstein: instancias y trazos. Socialismo y Participación. Lima: CEDEP, n. 98, 173-179, set. 2004b.

47. QUIJANO, Aníbal. Diálogo sobre la crisis y las ciencias sociales en América Latina. Entrevista de Jaime Ríos. Sociológica. Revista del Colegio de Sociólogos del Perú. Lima, n. 1, v. 1, p. 19-41, ago. 2009.

48. QUIJANO, Aníbal. Colonialidade de poder e classificação social. In: SANTOS, Boaventura de S.; MENESES, Maria P. (Orgs.) Epistemologias do sul. São Paulo: Cortez, 2010, p. 84-130.

49. QUIJANO, Aníbal. Cuestiones y horizontes: de la dependencia históricoestructural a la colonialidad/descolonialidad del poder. Organização e prefácio de Danilo A. Clímaco. Buenos Aires: CLACSO, 2014.

50. QUIJANO, Aníbal; WALLERSTEIN, Immanuel. La americanidad como concepto, o América en el moderno sistema mundial. Revista Internacional de Ciencias Sociales, Espanha-UNESCO, v. XLIV, n. 4, p. 583-592, dez.1992.

51. QUINTERO, Pablo. Heterogeneidad histórico-estructural, dependencia y colonialidad del poder: la crítica al desarrollo desde el andamiaje teórico de Aníbal Quijano. In: PACHECO CHÁVEZ, Victor H. (Org.). Rompiendo la jaula de la dominación: ensayos en torno a la obra de Aníbal Quijano. Santiago: Doble Ciencia Editorial, 2018, p. 125-161.

52. RUBBO, Deni A. Aníbal Quijano e a racionalidade alternativa na América Latina: diálogos com Mariátegui. Estudos Avançados, São Paulo, v. 32, n. 94, p. 391-409, dez. 2018a. doi: 10.1590/s0103-40142018.3294.0025

53. RUBBO, Deni A. O labirinto periférico: José Carlos Mariátegui e a sociologia crítica latino-americana. Tese (Doutorado em Sociologia) - Faculdade de Filosofia, Letras e Ciências Humanas, Universidade de São Paulo. São Paulo, 2018 b.

54. SOCIEDAD Y POLÍTICA. Editorial. Sociedad y Política. Lima, v. 3, n. 8, fev. 1980 .

55. THERBORN, Göran. Do marxismo ao pós-marxismo? São Paulo: Boitempo, 2012.

56. TOSEL, André. Le marxisme du 20 siècle. Paris: Syllepse, 2009.

57. TRAVERSO, Enzo. Melancolia de esquerda: marxismo, história e memória. Belo Horizonte: Âyiné, 2018.

58. WEFFORT, Francisco; QUIJANO, Aníbal. Populismo, marginalización y dependencia: ensayos de interpretación sociológica. Costa Rica: Educa, 1973. 
59. ZEVALLOS, Enrique A. Aníbal Quijano (1930-2018), Instituto de Estudos Avançados e o contexto peruano. Estudos Avançados, IEA-USP, v. 32, n. 94, São Paulo, p. 411-427, set./dez. 2018. doi: 10.1590/s0103-40142018.3294.0026.

Recebido: 28 jan. 2019

Aceito: 26 ago. 2019 